7 Q2 Ferenc Báthori ${ }^{\mathrm{a}}$, Enikő Csata ${ }^{\mathrm{a}, \mathrm{b}}$, András Tartally ${ }^{\mathrm{a}, *}$

a Department of Evolutionary Zoology and Human Biology, University of Debrecen, Egyetem Tér 1, H-4032 Debrecen, Hungary

${ }^{\mathrm{b}}$ Hungarian Department of Biology and Ecology, Babeş-Bolyai University, Clinicilor 5-7, 400006 Cluj-Napoca, Romania

\title{
Rickia wasmannii increases the need for water in Myrmica scabrinodis
} (Ascomycota: Laboulbeniales; Hymenoptera: Formicidae)

\begin{abstract}
A B S T R A C T
The order Laboulbeniales (Fungi, Ascomycota) is a little-studied group of microscopic ectoparasites of invertebrates, mostly insects. The effects of Laboulbeniales species on their hosts are mostly unknown. Rickia wasmannii Cavara, 1899 is a common Laboulbeniales fungus occurring in Europe and is currently known to be a parasite of at least eight Myrmica ant species. $R$. wasmannii serves as a good model organism for Laboulbeniales-host interactions, as this species covers the host in a very high density, and infected host individuals can be easily collected in high numbers. The effect of $R$. wasmannii on the survival rate of its most common host species, Myrmica scabrinodis Nylander 1846, was therefore investigated in a laboratory experiment on an individual level. To enhance the results, environmental stresses were simulated by depriving infected and uninfected workers of water and food. The survival of individuals was recorded hourly until the death of the last individual. Infected specimens were significantly more sensitive to the withdrawal of food and water than uninfected specimens. When we tested for water consumption, we found that infected ants spent more time consuming water than uninfected ants. Therefore, it is possible that infected ants must replace the loss of water. Based on these results, $R$. wasmannii substantially decreases the chances and time of survival of infected individuals, at least in resource-limited environments, which suggest that $R$. wasmannii has a negative effect on its host.
\end{abstract}

(c) 2015 Published by Elsevier Inc.

\section{Introduction}

The Laboulbeniales are an ascomycetous order of fungi comprising 140 genera and more than 2000 species (Rossi and Santamaria 2012). They are obligate ectoparasites of arthropods, especially insects. Laboulbeniales fungi parasitize at least twelve different insect orders but most commonly (about $90 \%$ of species) they parasitize Coleoptera and Diptera (Henk et al., 2003; Santamaria, 2001). They are basically thought to be spread via direct contact between individual hosts (e.g., Cottrell and Riddick, 2012; De Kesel, 1996). Most Laboulbeniales fungi exhibit extreme host-specificity; the host spectrum ranges from single (stenotopic) to multiple host species (eurytopic) (Haelewaters et al., 2012 and references therein). In contrast with most fungus species, only the sexual stages of Laboulbeniales have been found (Haelewaters, 2012). Little is known about the effect of Laboulbeniales fungi on their host species. Espadaler and Santamaria (2012) mention their "ability to grow on their hosts without inflicting any noticeable injury". They are sometimes

\footnotetext{
* Corresponding author. Tel.: +36 52316 666/62349, cell: +36 203235810 (non-public); fax: +3652512941.

E-mail address: tartally.andras@science.unideb.hu (A. Tartally).
}

considered to be a neutral factor (Garcia et al., 2010; LapevaGjonova and Santamaria, 2011; Whisler, 1968), or to cause little to no harm (Benjamin, 1971; Majewski, 1994; Santamaria, 1998; Scheloske, 1969). Negative effects are also mentioned (Benjamin, 1971; Nalepa and Weir, 2007; Raak-van den Berg et al., 2014; Riddick, 2010, 2006). Gemeno et al. (2004) found some negative effects of a Laboulbeniales fungus on a cockroach and Strandberg and Tucker (1974) in an earwig species. However, the infection rate on the hosts and the number of infected individuals are usually too small to study such questions in wild populations.

Ants are the only known hosts of Laboulbeniales in the order Hymenoptera (Espadaler and Santamaria, 2003). Four species of Laboulbeniales fungi have been reported so far to parasitize ants in Europe: Rickia wasmannii Cavara (Fig. 1) in 15 countries; Laboulbenia formicarium Thaxt. in France, Portugal, and Spain; Laboulbenia camponoti S.W.T. Batra in Austria, Bulgaria, Hungary, and Spain; and Rickia lenoirii Santam. in Greece and France (Espadaler and Santamaria, 2012; Haelewaters, 2012; Báthori et al., 2014; Santamaria and Espadaler, 2015). R. wasmannii was understudied for a long time, but in recent years more reports on its distribution and host ant usage (for a review about both topics: Espadaler and Santamaria, 2012) have been published, and these have shown $R$. 
wasmannii to be the most widely distributed of the four ant-parasitizing Laboulbeniales species in Europe. Reports from England, France, Germany, Luxembourg, the Netherlands, Switzerland, Poland, Italy, Austria, Slovenia, the Czech Republic, Slovakia, Hungary, Romania and Bulgaria have shown R. wasmannii populations parasitizing eight species of the Myrmica Latreille 1804 (Hymenoptera: Formicidae) genus: Myrmica slovaca Sadil, 1952; M. scabrinodis Nylander, 1846 (Fig. 1); M. specioides Bondroit, 1918; M. vandeli Bondroit, 1920; M. rubra (Linnaeus, 1758); M. sabuleti Meinert, 1861; M. gallienii Bondroit, 1920 and M. ruginodis Nylander, 1846 (Espadaler and Santamaria, 2012; Haelewaters, 2012; Csata et al. 2013; Santamaria and Espadaler, 2015). In Hungary, it is the only ant-parasitizing Laboulbeniales species found (Tartally et al., 2007).

Despite the increasing number of papers describing the distribution of $R$. wasmannii (Csata et al., 2013; Espadaler and Santamaria, 2012, and references herein; Haelewaters, 2012), there is little information about the interactions between this fungus and its hosts. As R. wasmannii is known to be the most widely distributed ant-parasitizing Laboulbeniales species in Europe (see above), and as highlyinfected M. scabrinodis (the commonest host in the Carpathian Basin: Csata et al., 2013; Tartally, 2008; Tartally et al., 2007) workers with this fungus can be easily collected in high numbers (pers. observ.), we surmised that $R$. wasmannii would be a good model organism of the Laboulbeniales order to study the interactions between Laboulbeniales fungi and their hosts, collected from wild (rather than laboratory, as in, e.g., Cottrell and Riddick, 2012; Gemeno et al., 2004) populations. One of the most important questions about such interactions is whether Laboulbeniales fungi have any negative or positive effects on the host organism. A recent paper has already demonstrated negative effects of the fungi on its $M$. scabrinodis host: workers infected with $R$. wasmannii, have a reduced lifespan, while they display increased allo-grooming behaviour (Csata et al., 2014). In this research, environmental stresses were simulated by withdrawing water and food from four groups of $M$. scabrinodis workers, two infected by $R$. wasmannii and two uninfected. The survival rate of these four groups without food and water, and their water consumption after water-deprivation were compared.

\section{Materials and methods}

\subsection{Ant colony collection}

Despite the intensive work of one of the authors (AT) on sites with $R$. wasmannii (see e.g. Tartally, 2008 and references therein), no single sites with highly infected and uninfected $M$. scabrinodis colonies were found in proportions that would have been useful in collecting infected and uninfected (control) colonies. We found that the known sites in Hungary contain almost exclusively highly-infected or uninfected colonies of host ant species. Accordingly, M. scabrinodis colonies were collected from marshy meadows of two different regions in Hungary in order to make comparisons in two cases. Twelve colonies were collected from northern Hungary (six infected colonies from Meszes: $48^{\circ} 27^{\prime} \mathrm{N}$, $20^{\circ} 47^{\prime} \mathrm{E}, 165 \mathrm{~m}$ a.s.l. and six uninfected colonies from Aggtelek: $48^{\circ} 26^{\prime} \mathrm{N}, 20^{\circ} 30^{\prime} \mathrm{E}, 340 \mathrm{~m}$ a.s.l.) and twelve others from eastern Hungary (six infected colonies from Újléta: $47^{\circ} 26^{\prime} \mathrm{N}, 21^{\circ} 51^{\prime} \mathrm{E}$, $120 \mathrm{~m}$ a.s.l. and six uninfected ones from Csíkgát at Monostorpályi: $47^{\circ} 25^{\prime} \mathrm{N}, 2^{\circ} 48^{\prime} \mathrm{E}, 108 \mathrm{~m}$ a.s.l.). All 24 colonies contained fertilized queens, hundreds of workers, larvae, and pupae. The ants were kept in artificial lab nests at $23 \pm 1{ }^{\circ} \mathrm{C}$ with complex food resources (cockroaches twice a week and honey water ad libitum). Plastic boxes were used as formicaria (length: $16.5 \mathrm{~cm}$, width: $11.5 \mathrm{~cm}$, height: $6 \mathrm{~cm}$; painted with Fluon ${ }^{\circledR}$ in the inner walls to prevent the ants from escaping). The box bottoms were covered with plaster, and they all contained a chamber (length: $5.5 \mathrm{~cm}$, width: $4.5 \mathrm{~cm}$, height: $1 \mathrm{~cm}$ ) covered by glass plates. All colonies were stored in the laboratory for a minimum of 1 month before the experiment as an acclimatisation period.

\subsection{Experimental design}

Five days before the experiment, 20 workers were randomly selected from each of the 24 colonies and moved together to open plastic boxes $(12 * 20$ infected and $12 * 20$ uninfected workers were selected $=480$ workers in total). The same boxes were used as above but without plaster. The boxes were uncovered to allow for evaporation. In order to make the research repeatable, the separated minicolonies were provided with Bhatkar diet (Bhatkar and Whitcomb, 1970) and water ad libitum $24 \mathrm{~h}$ before monitoring. After $24 \mathrm{~h}$, all food and water were withdrawn, and each mini-colony was checked hourly by counting the number of dead workers. A specimen was considered to be dead when it did not move its legs or antennae after they were touched with forceps. Dead individuals were removed from the mini-colonies following the hourly counting. During the experiment the room temperature $\left(23.4-24.2{ }^{\circ} \mathrm{C}\right.$ ) and humidity (35-39\%) were recorded hourly. The experiment ended with the death of the last individual ( $55 \mathrm{~h}$ after the beginning). By the end of the experiment, the fungal thalli on the dead infected

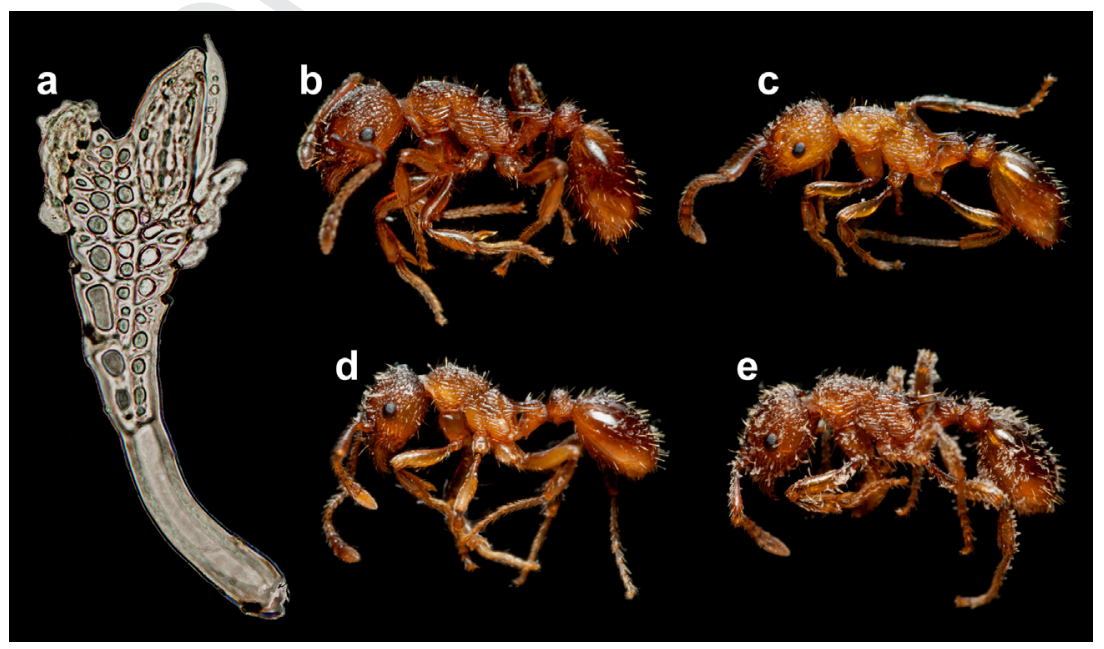

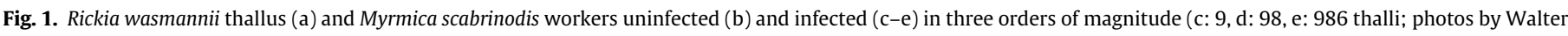
P. Pfliegler). 
individuals were counted under a Leica MZ12.5 stereomicroscope at magnifications of $10 \times-160 \times$.

To test whether the limiting factor of the survival of the ants was the deprivation of water only or also the deprivation of food, a control experiment was carried out in which food was withheld but water was provided ad libitum. This experiment involved a total of 480 specimens, 20 individuals from each of the 12 infected and 12 uninfected colonies described above. This experiment ended $55 \mathrm{~h}$ (see the end of the previous paragraph) after food deprivation, when the number of dead individuals was counted in each nest. The opposite control experiment was not possible because of the water content of the food.

In the third part of the research, the water consumption of infected and uninfected $M$. scabrinodis workers was tested under laboratory conditions. We measured the time that one individual spent consuming water after a minimum of $12 \mathrm{~h}$ of water deprivation using the same 24 ant colonies described above. For this experiment, 20 individuals were selected from each nest to form mini-colonies. After $12 \mathrm{~h}$ of water deprivation, 240 uninfected and 213 infected workers survived, and they were all moved separately and randomly to different test tubes (length $=53 \mathrm{~mm}$, $d=15 \mathrm{~mm}$ ). After a one-minute acclimatisation period $0.05 \mathrm{ml}$ of water was introduced into the test tubes and the ants were given three minutes to discover it. The individuals that did not discover the water within this three-minute period were excluded from the test (16 infected and 11 uninfected). Thus, we worked practically with 197 infected and 229 uninfected M. scabrinodis workers. The length of time a worker spent in the first round of water consumption was noted in the case of all 426 individuals.

\subsection{Statistical analyses}

Statistical analyses were carried out using R statistical software (R Development Core Team R, 2011). To compare the survival curves Mixed Effect Cox regressions (Cox, 1972 as implemented in the coxme add-on package in $\mathrm{R}$ (Therneau, 2012)) were used. The Generalized Linear Mixed Model (GLMM, Poisson error, maximum likelihood fit) approach was applied to test the effects of infection on the water consumption of individuals. The length of time an individual was deprived of water before the water consumption experiments was introduced as a covariate. The interaction between the length of this period of time and the infection status of the observed individuals was also taken as a covariate. For the survival rates of infected and uninfected ants, in both cases (Cox regression and GLMMs) colony identity was included as a random factor, and the infection status of the ants (infected vs. uninfected), habitat type (Újléta, Meszes, Csíkgát, Aggtelek) and categories of fungal thalli were included as a dummy variable. GLMMs were performed using glmer function in the lme4 package (Bates et al., 2014). In the case of survival of the infected ants, they were categorized according to the number of fungal thalli (see examples at: Fig. 1) on an individual level. Fifty categories were created for infected ants by scale 20 ("category 1": 1-20 thalli, "category 2": 21-40 thalli and so on up to "category 50": 981-1000 thalli). No other categories were necessary because the highest recorded number of thalli was 986 per individual. Uninfected individuals were assigned to "category 0". Bonferroni Holm correction was used to determine the levels of significance when Cox regression (population level) and GLMM (category level) analyses were performed.

\section{Results}

While the first infected worker died $5 \mathrm{~h}$ after the beginning of the experiment and the last $28 \mathrm{~h}$ later ( $33 \mathrm{~h}$ after the beginning of the experiment), the first uninfected worker died $12 \mathrm{~h}$ after the start of the experiment and the last one $43 \mathrm{~h}$ later ( $55 \mathrm{~h}$ after the beginning of the experiment). When the infected workers (Újléta and Meszes) were compared as a group with the uninfected ones (Csíkgát and Aggtelek), the lifespan of the uninfected workers was found to be significantly higher (Cox regression, coeff $=1.45$, $\exp ($ coef $)=4.30, z=13.58, p<0.0001, n=468)$. When uninfected and infected workers were compared at the population level, similar results were found, since survival rates of the two infected populations, Meszes and Újléta, were significantly different from survival rates of the two uninfected populations, Csíkgát and Aggtelek (Fig. 2: Meszes: $z=-6.63, p<0.0001$; Újléta: $z=-4.81$, $p<0.0001)$. However, no significant differences were found between the infected Újléta and Meszes populations $(z=-0.28$, $p=0.77$ ). The same results were obtained in the case of uninfected populations, as there were no significant differences between the Csíkgát and Aggtelek populations $(z=-1.19, p=0.46)$. The number of fungus thalli had a significant effect on the survival rate of the infected individuals $(z=-7.39, p<0.0001)$. Thus, heavily parasitized individuals died significantly more rapidly than lightly parasitized individuals. As a comparison of the lifespans of uninfected and infected workers on the basis of the infection categories revealed, individuals belonging to the higher categories ("category 2-50") of infection died significantly more rapidly than those from "category 0" (Fig. 3: GLMM: $z=-8.25, p<0.0001, n=468$ ). Infected individuals from "category 2 " died significantly more rapidly (GLMM: $z=-2.39, p=0.03$ ) than uninfected ones from "category 0 ". In the second experiment, when only food was withheld, only 35 dead specimens were recorded among the 240 infected ants (14.58\% mortality rate) and 4 among the 240 uninfected individuals (1.66\% mortality rate).

In the case of water consumption, a significant difference was found between the populations from Aggtelek and Meszes, as infected individuals spent more time consuming water than uninfected ones (GLMM: $z=2.72, p=0.006, n=197$ ). Similar differences were found between populations from Újléta and Csíkgát (GLMM: $z=3.91, p=0.001, n=229$ ). By analysing all the infected (Újléta and Meszes) workers in comparison with all the uninfected workers (Csíkgát and Aggtelek), the results also showed that infected individuals spent significantly more time consuming water than uninfected ones (Fig. 4 : GLMM, $z=5.4, p=0.001$ ).

\section{Discussion}

The results (Fig. 2 and 3) clearly show that $R$. wasmannii has a negative effect on the survival rate of $M$. scabrinodis, at least under

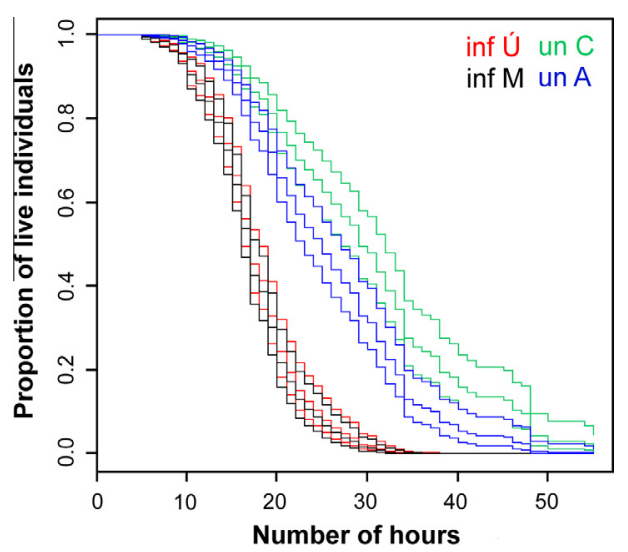

Fig. 2. The lifespan of infected (inf) and uninfected (un) Myrmica scabrinodis workers from four populations: Újléta (Ú), Meszes (M), Csíkgát (C) and Aggtelek (A). Broken lines represent a point-wise 95-percent confidence interval around the corresponding functions. 


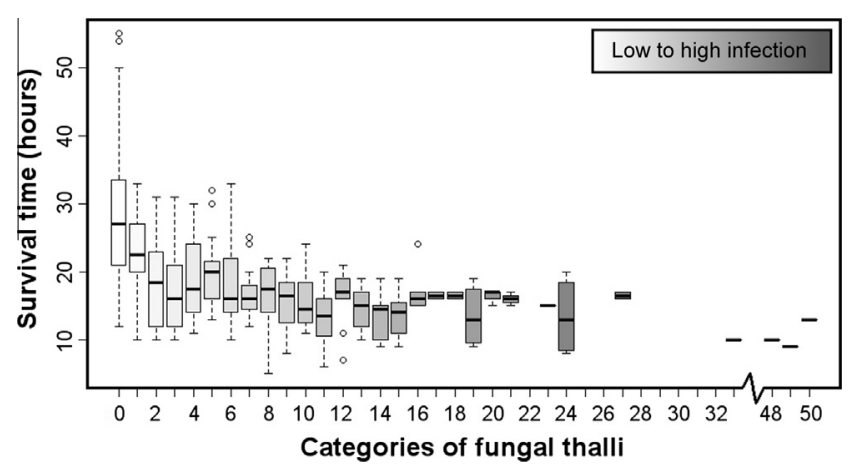

Fig. 3. Survivorship of all the analysed (see Fig. 2) M. scabrinodis workers ordered into 51 categories of infection (uninfected: "category 0 "; infected: "category 1 ": 1 20 thalli, "category 2": 21-40 thalli and so on up to "category 50": 981-1000 thalli).

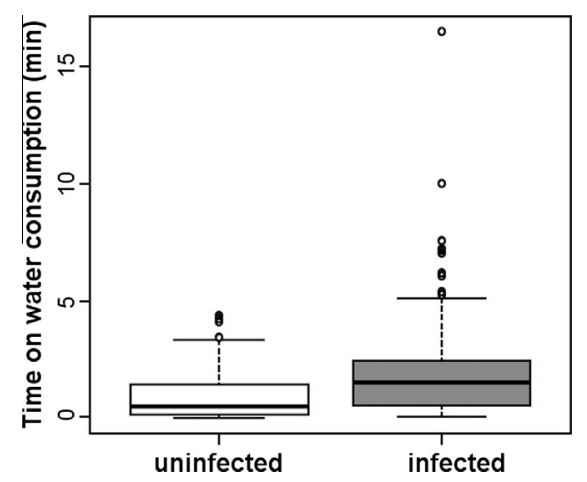

Fig. 4. Individual time (min) spent on water consumption in infected and uninfected populations.

laboratory conditions when water and food are not available. Similarly, with regards to water consumption the analysis showed that infected ants spent significantly more time consuming water than uninfected ants (Fig. 4).

We obtained these results from two different regions, but further similar research would be useful involving sites in which both infected and uninfected colonies are available in high numbers. It is not clear whether the effect of $R$. wasmannii on M. scabrinodis is so clearly negative under natural conditions, since, for example, the ants can dig down to wet soil in drier periods (Scherba, 1959). However, we can conclude that $R$. wasmannii has an influence on the physiology of $M$. scabrinodis. Further research is necessary to investigate the background of this influence. Possible options are (1) direct metabolic effects on the ants; (2) absorption of water from the hemolymph by fungal thalli; (3) the fungi create the conditions for intensified evaporation (as in the case of cockroaches: Gemeno et al., 2004); (4) the fungi place an additional burden on the ants, which increases the metabolic rates in the ants as they need extra energy in order to bear the additional weight; (5) the thalli on/around the mandibles prevent the ants from consuming water (see: Nalepa and Weir, 2007). Whatever the explanation may be, it seems clear that the ants must replace lost water, and this constitutes a negative effect of this fungus on the ant host. The results from $M$. scabrinodis individuals confirm the recent results of Csata et al. (2014), according to which $R$. wasmannii has a negative effect on $M$. scabrinodis.

As far as we know, these are among the first (see also Csata et al., 2014) results indicating the effects of an ant-parasitizing Laboulbeniales fungus on host ants. It would be useful to repeat such experiments on other ant-parasitizing Laboulbeniales species, such as $L$. formicarum. Ants infected by this fungus are also readily available in high numbers (Herraiz and Espadaler, 2007), but the other two European ant-parasitizing Laboulbeniales fungi are rather rare (Báthori et al., 2014; Espadaler and Santamaria, 2012; Santamaria and Espadaler, 2015) for the purposes of such research. Furthermore, it would also be useful to test for the negative effect of $R$. wasmannii not only on M. scabrinodis but also on other Myrmica species.

There are several ant-parasitizing fungi in different taxonomic groups (see e.g. Csata et al., 2013; Espadaler and Santamaria, 2012, and references therein), and based on our results $R$. wasmannii can also be defined as a parasite. However, it is not clear whether biological control of invasive ant species could be accomplished using $R$. wasmannii or other ant-parasitizing fungi, such as L. formicarum, which infects the invasive Lasius neglectus in Europe (see e.g.: Espadaler and Santamaria, 2012). Another example of insect-parasitizing Laboulbeniales fungi with potential as a biological control agent is Hesperomyces virescens Thaxt., which has a negative effect on the survival of the invasive Harmonia axyridis Pallas, 1773 ladybird males during wintering (Riddick, 2010; see: Raak-van den Berg et al., 2014 and its Supplementary material 1 for a review of negative effects of $H$. virescens on $H$. axyridis). In some cases, premature death or reduced fecundity has been observed (Bro Larsen, 1952; Kamburov et al., 1967a, 1967b). Further research on this question would also be useful in the case of invasive ants, but the potential positive results could be applied only after a strict control, because proper experiments should be done in order to determine if only the invasive, and not the native, ant species can be infected by any non-native pathogens.

The eight Myrmica species (see Section 1) currently known to be parasitized by $R$. wasmannii are widespread across Europe, although they are often found in small, isolated populations (Radchenko and Elmes, 2010). These host species are closely associated with other arthropods (see: Witek et al., 2014 for a review), for instance Microdon spp. (Diptera: Syrphidae), Maculinea spp. (Lepidoptera: Lycaenidae) and their ichneumon parasites (Ichneumon spp. and Neotypus spp.; Hymenoptera: Ichneumonidae), the latter often occurring where $R$. wasmannii are found (see: Appendix III of Tartally 2008). This implies that other arthropods might be potential vectors of $R$. wasmannii as long as they share the same habitat (sensu De Kesel and Haelewaters, 2014; Santamaria and Espadaler, 2015), but this is still an open question. Morphological and ecological evidence for host shift of Laboulbeniales species between unrelated but cohabiting host species was recently provided in De Kesel and Haelewaters (2014). Furthermore, these Myrmica-associated arthropods are often endangered (e.g. Munguira and Martín, 1999); therefore, a better understanding of the ecology of the "fungus-ant-social parasite system" is of crucial importance from a conservation biological point of view. Our results show that ants infected with $R$. wasmannii were less resistant to the absence of food and water (Figs. 2 and 3). Thus it is highly plausible that infected colonies have serious disadvantages against competitors and social parasites in their natural environments, a fascinating topic for future investigation.

According to Fig. 3, the heavier the parasitizing, the lower the survival rate. This finding confirms Crofton (1971a,b), who proposed that the death of hosts results only when hosts are heavily parasitized, when the reproductive potential of parasites exceeds that of the hosts, and when their frequency distribution is over-dispersed within host populations (i.e. when variance of fungal populations is significantly greater than the mean). This is because parasites (macroparasites in particular) tend to concentrate on a minority of heavily infested individuals (Clayton et al. 2003). By combining aspects of death and the dispersion of populations, Crofton (1971a,b) quantified and distinguished parasites from pathogens. According to these findings, further studies would be necessary on other Laboulbeniales species to conclude whether 
they adopt a life history strategy similar to those of other parasites, with the potential for pathogenicity only when numbers are high within a given host individual.

The findings of earlier studies (e.g. Csata et al., 2014; Gemeno et al., 2004; Riddick, 2010; Strandberg and Tucker, 1974), according to which Laboulbeniales fungi can have a negative effect on the survival rates of their hosts, are confirmed (Figs. 2-4). We therefore hope that the recent results showing the negative effect of $R$. wasmannii on the survival rates of M. scabrinodis will be of interest from myrmecological, mycological, and parasitological viewpoints.

\section{Acknowledgments}

We are grateful to Vivien Márku, Zsófia Tóth, Zoltán Rádai, Anna Ágnes Somogyi and Krisztina Varga for their help in our field and laboratory work, to Orsolya Vincze, Bálint Markó, Enikő Tóth and three anonymous referees for providing valuable comments on our manuscript and to Walter Pfliegler for the photos used for the Graphical abstract and Fig. 1. All co-authors were supported by the 'AntLab' Marie Curie Career Integration Grant (of AT) within the 7th European Community Framework Programme. AT was supported by a 'Bolyai János' scholarship of the Hungarian Academy of Sciences (MTA). ECs was supported by the scholarships of Collegium Talentum and also by scholarships provided in the framework of TÁMOP-4.2.4.A/ 2-11/1-2012-0001 "National Excellence Program" offered by the European Union and the State of Hungary, co-financed by the European Social Fund.

\section{References}

Bates, D., Maechler, M., Bolker, B., Walker, S., 2014. Ime4 package. Linear mixedeffects models using Eigen and S4. Retrieved from <http://lme4.r-forge.rproject.org/>, published online on 02.02.2014.

Báthori, F., Pfliegler, W.P., Tartally, A., 2014. First records of the myrmecophilous fungus Laboulbenia camponoti Batra (Ascomycetes: Laboulbeniales) from Austria and Romania. Sociobiology 61 (3), 338-340. http://dx.doi.org/ 10.13102/sociobiology.v61i3.338-340.

Benjamin, R.K., 1971. Introduction and supplement to Roland Thaxter's contribution towards a monograph of the Laboulbeniaceae. Bibliotheca Mycol., 30

Bhatkar, A., Whitcomb, W.H., 1970. Artificial diet for rearing various species of ants. Florida Entomol. 55, 229-232.

Bro Larsen, E., 1952. On subsocial beetles from the salt-marsh, their care of progeny and adaptation to salt and tide. In: Transactions of the IX International Congress of Entomology, Amsterdam, vol. 1. pp. 502-506.

Clayton, D.H., Al-Tamimi, S., Johnson, K.P., 2003. The ecological basis of coevolutionary history. In: Page, R.D.M. (Ed.), Tangled Trees: Phylogeny, Cospeciation and Coevolution. University of Chicago Press, Chicago, pp. 310341.

Cottrell, T.E., Riddick, E.W., 2012. Limited transmission of the ectoparasitic fungus Hesperomyces virescens between lady beetles. Psyche, 1-7. http://dx.doi.org/ 10.1155/2012/814378. Article ID 814378.

Cox, D.R., 1972. Regression models and life tables (with Discussion). J. R. Stat. Soc. Ser. B 34, 187-220.

Crofton, H.D., 1971a. A quantitative approach to parasitism. Parasitology 62, 179193. http://dx.doi.org/10.1017/S0031182000071420.

Crofton, H.D., 1971b. A model for host-parasite relationships. Parasitology 63, 343 364. http://dx.doi.org/10.1017/S0031182000079890.

Csata, E., Czekes, Zs., Erős, K., Német, E., Hughes, M., Csősz, S., Markó, B., 2013. Comprehensive survey of Romanian myrmecoparasitic fungi: new species, biology and distribution. North-West. J. Zool. 9 (1), 23-29.

Csata, E., Erős, K., Markó, B., 2014. Effects of the ectoparasitic fungus Rickia wasmannii on its ant host Myrmica scabrinodis: changes in host mortality and behavior. Insect. Soc. 61 (3), 247-252. http://dx.doi.org/10.1007/s00040-0140349-3.

De Kesel, A., 1996. Relative importance of direct and indirect infection in the transmission of Laboulbenia slackensis (Ascomycetes, Laboulbeniales). Belg. J. Bot. 128, 124-130.

De Kesel, A., Haelewaters, D., 2014. Laboulbenia slackensis and L. littoralis sp. nov. (Ascomycota, Laboulbeniales), two sibling species as a result of ecological speciation. Mycologia 106 (3), 407-414.

Espadaler, X., Santamaria, S., 2003. Laboulbenia formicarium Thaxt. (Ascomycota, Laboulbeniales) crosses the Atlantic. Orsis 18, 97-101.
Espadaler, X., Santamaria, S., 2012. Ecto- and endoparasitic fungi on ants from the Holartic Region. Psyche, 1-10. http://dx.doi.org/10.1155/2012/168478. Article ID 168478.

Garcia, F., Espadaler, X., Echave, P., Vila, R., 2010. Hormigas (Hymenoptera, Formicidae) de los acantilados de l'Avec de Tavertet Barcelone, Peninsula Iberica. Boletin de la Sociedad Entomologica Aragonesa 47, 363-367.

Gemeno, C., Zurek, L., Schal, C., 2004. Control of Herpomyces spp. (Ascomycetes: Laboulbeniales) infection in the wood cockroach, Parcoblatta lata (Dictyoptera: Blattodea: Blattellidae), with benomyl. J. Inverbr. Pathol. 85, 132-135.

Haelewaters, D., 2012. The first record of Laboulbeniales (Fungi, Ascomycota) on ants (Hymenoptera, Formicidae) in The Netherlands. Ascomycete.org. 4 (3), 6569.

Haelewaters, D., van Wielink, P., van Zuijlen, J.-W., Verbeken, A., De Kesel, A., 2012. New records of Laboulbeniales (Fungi, Ascomycota) for The Netherlands. Entomologische Berichten 72 (3), 175-183.

Henk, D.A., Weir, A., Blackwell, M., 2003. Laboulbeniopsis termitarius, an ectoparasite of termites newly recognized as a member of the Laboulbeniomycetes. Mycologia 95 (4), 561-564.

Herraiz, J.A., Espadaler, X., 2007. Laboulbenia formicarium (Ascomycota, Laboulbeniales) reaches the Mediterranean. Sociobiology 50 (2), 449-455.

Kamburov, S.S., Nadel, D.J., Kenneth, R., 1967a. Observations on Hesperomyces virescens Thaxter (Laboulbeniales) a fungus associated with premature mortality of Chilocorus bipustulatus L. in Israel. Israel J. Agr. Res. Rehovot. 17 $131-134$.

Kamburov, S.S., Nadel, D.J., Kenneth, R., 1967b. Studies on the fungus Hesperomyces virescens attacking Chilocorus bipustulatus. In: Research Report, 1965, 1966 , Plant Pathology. Hebrew University, Faculty of Agriculture, Jerusalem, pp. 623642, pp. 635-636.

Lapeva-Gjonova, A., Santamaria, S., 2011. First records of Laboulbeniales (Ascomycota) on ants (Hymenoptera: Formicidae) in Bulgaria. ZooNotes 22, $1-6$.

Majewski, T., 1994. The occurrence of the Laboulbeniales [Fungi, Ascomycetes] in natural forest communities in the Czasopismo. Fragmenta Floristica et Geobotanica 39 (2), ISSN 0015-931X.

Munguira, M.L., Martín, J., (Eds) 1999. Action plan for the Maculinea butterflies in Europe. Nature and Environment, No 97. Council of Europe Publishing, Strasbourg, p. 64.

Nalepa, C.A., Weir, A., 2007. Infection of Harmonia axyridis (Coleoptera: Coccinellidae) by Hesperomyces virescens (Ascomycetes: Laboulbeniales): role of mating status and aggregation behaviour. J. Inverbr. Pathol. 94, 196-203.

R Development Core Team, 2011. R: A language and environment for statistical computing. R Foundation for Statistical Computing, Vienna, Austria. <http:// www.R-project.org/> (accessed 12.12.2014).

Raak-van den Berg, C.L., Wielink, P.S., Jong, P.W., Gort, G., Haelewaters, D., Helder, J. Karssen, G., Lenteren, J.C., 2014. Invasive alien species under attack: natural enemies of Harmonia axyridis in the Netherlands. Biocontrol 59 (2), 229-240.

Radchenko, A.G., Elmes, G.W., 2010. Myrmica (Hymenoptera: Formicidae) ants of the Old World. Fauna Mundi 3, 1-789.

Riddick, W.E., 2006. Influence of host gender on infection rate, density and distribution of the parasitic fungus, Hesperomyces virescens, on the multicolored Asian Lady Beetle, Harmonia axyridis. J. Insect. Sci. 6 (42), 1-15. http:// dx.doi.org/10.1673/031.006.4201.

Riddick, W.E., 2010. Ectoparasitic mite and fungus on an invasive lady beetle: parasite coexistence and influence on host survival. Bull. Insectol. 63 (1), 13-20.

Rossi, W., Santamaria, S., 2012. Rodaucea, a new genus of the Laboulbeniales. Mycologia 104 (3), 785-788.

Santamaria, S., 1998. Laboulbeniales, I. Laboulbenia. Fl. Mycol. Iber. 4, 1-186.

Santamaria, S., 2001. Los Laboulbeniales, un grupo enigmático de hongos parásitos de insectos. Lazaroa 22, 3-19.

Santamaria, S., Espadaler, X., 2015. Rickia lenoirii, a new ectoparasitic species, with comments on world Laboulbeniales associated with ants. Mycoscience 67, 56, http://dx.doi.org/10.1016/j.myc.2014.06.006 (in press).

Scheloske, H.W., 1969. Beiträge zur Biologie, Ökologie und Systematik der Laboulbeniales (Ascomycetes): unter besonderer Berücksichtigung des Parasit-Wirt-Verhältnisses. Parasitol Schriftenreihe, p. 176.

Scherba, G., 1959. Moisture regulation in mound nests of the ant. Formica ulkei Emery. Am. Midl. Nat. 6, 499-508.

Strandberg, J.O., Tucker, L.C., 1974. Filariomyces forficulae: occurrence and effects on the predatory earwig, Labidura riparia. J. Invertebr. Pathol. 24, 357-364.

Tartally, A., 2008. Myrmecophily of Maculinea butterflies in the Carpathian Basin (Lepidoptera: Lycaenidae). PhD Thesis, University of Debrecen, Debrecen, p. 97.

Tartally, A., Szücs, B., Ebsen, J.R., 2007. The first records of Rickia wasmannii Cavara, 1899, a myrmecophilous fungus, and its Myrmica Latreile, 1804 host ants in Hungary and Romania (Ascomycetes: Laboulbeniales, Hymenoptera: Formicidae). Myrmecol. News 10, 123.

Therneau, T., 2012. Coxme package. Mixed Effects Cox Models. Retrieved from $<$ http://r-forge.r-project.org>, published online on 15.05.

Whisler, H.C., 1968. Experimental studies with a new species of Stigmatomyces (Laboulbeniales). Mycologia 60, 65-75.

Witek, M., Barbero, F., Markó, B., 2014. Myrmica ants host highly diverse parasitic communities: from social parasites to microbes. Insect. Soc. 61, 307-323. http://dx.doi.org/10.1007/s00040-014-0362-6.
440 